\title{
HANNAH ARENDT E AS CONDIÇÕES ESSENCIAIS AO TOTALITARISMO: A SOCIEDADE DE MASSA E O TERROR
}

Douglas Antônio Zorzo ${ }^{1}$

Resumo: Os regimes totalitários são uma marca indelével de nosso tempo. A ascensão dos totalitarismos e o modo por meio do qual esses sistemas puderam se solidificar enquanto formas de governo levantam uma série de questionamentos acerca das relações políticas e de poder. Nesse sentido, o alvorecer do totalitarismo e a cooptação dos indivíduos ao redor dos propósitos desses governos revela-se como um solo fecundo para uma investigação. O intuito do artigo aqui apresentado é tentar explorar, através do pensamento da filósofa alemã Hannah Arendt, duas condições essenciais para o surgimento e a manutenção desses totalitarismos: a sociedade de massa e a operacionalidade do terror. Para isso, em primeiro lugar, buscamos descrever, mesmo que resumidamente, a sociedade de massa e o modo através do qual ela constitui a base para o princípio dos sistemas totalitários. Isto é, como a transformação da sociedade de classes em uma sociedade de massa é o aspecto societário primeiro para esse alvorecer. Em segundo lugar, visamos delinear o lugar que o elemento do terror ocupa para a estruturação desses regimes e como opera para solidificá-los; ou seja, apresentar a função essencial do terror no processo de cooptação da massa.

Palavras-Chave: Hannah Arendt; Totalitarismo; Sociedade de massa; Terror.

Abstract: The totalitarian regimes are an indelible mark of our time. The ascent of the totalitarianism and the manner which these systems were able to solidify themselves as forms of government raise a number of questions about the political relations and power. In this sense, the dawn of the totalitarianism and the cooptation of individuals around the purposes of these governments may reveal itself as a fertile ground for research. The objective of the article presented here is to try to explore, through the thought of German philosopher Hannah Arendt, two essential conditions for the emergence and maintenance of these totalitarianisms: the mass society and the operation of terror. For this, first of all, we seek to describe briefly the mass society and the way in which it forms the basis for the principle of totalitarian systems. That is, as the transformation of the class society in a mass society is the first societal aspect to this dawn. Secondly, we aim to delineate the place that occupies the element of terror for structuring these regimes and how it operates to strengthen them; namely, to present the essential function of the terror in the process of the mass cooptation.

Keywords: Hannah Arendt; Totalitarianism; Mass society; Terror.

Os debates que orbitam os regimes totalitários despertam uma atenção particular nas sociedades contemporâneas. Embora o conceito de "totalitarismo" tenha ressurgido, com notável vigor, em um cenário de discussões que remonta ao final da década de 80, dificilmente podemos sustentar que ele tenha permanecido inerte no espaço que precede esse

\footnotetext{
${ }^{1}$ Doutorando em Filosofia pela Universidade Estadual do Oeste do Paraná- UNIOESTE/Toledo. Contato: douglasfedel@gmail.com
} 
"renascimento". Por certo, os fenômenos históricos totalitários agora possuem uma materialidade documental mais extensa, de modo que testemunhamos uma maior propensão de se tornarem o objeto de estudos, que visam deslindar os mecanismos de funcionamento de cada regime. Mas, além disso, o assombroso modus operandi desses acontecimentos desperta um sentimento de receio - com fundamentos concretos, ou não - de que esses governos são uma experiência que poderão voltar a ocorrer. Ou seja, a compreensão dos eventos que aconteceram no rebote da Grande Guerra, e que desembocaram nos episódios mais atrozes da Humanidade, oferece uma proposta para um duplo anseio: quais são as características de funcionamento desses regimes? Quais são as chances da história repetir-se?

A perplexidade que nos arrebata diante dos episódios totalitários está, ao menos parcialmente, no fato de que esses regimes são frutos de nosso tempo e surgem no interior de uma sociedade de massa. Essa preocupação está assentada, então, no envolvimento das massas para a constituição e a manutenção dos totalitarismos. Nesse sentido, o registro de Hannah Arendt em sua obra acerca das Origens do Totalitarismo é de uma urgência quase natural. Ora, é "muito perturbador o fato de o regime totalitário, malgrado o seu caráter evidentemente criminoso, contar com o apoio das massas" (ARENDT, 2012, p. 712, nota 1).

É justamente diante desse quadro de preocupações teóricas que desenvolvemos o trabalho aqui apresentado. Nosso esforço reside na tentativa de explorar o argumento de que a sociedade de massa e a operacionalidade do terror são condições essenciais para o surgimento e a manutenção dos totalitarismos. Isto é, buscamos caracterizar a sociedade de massa sobre a qual os regimes totalitários se constroem e os mecanismos utilizados para integrar os indivíduos e colocá-los em movimento. Para isso, possuímos duas intenções específicas. Em primeiro lugar, buscaremos descrever, ainda que sumariamente, a sociedade de massa e o modo através do qual ela pôde servir de base para o princípio dos sistemas totalitários. Em segundo lugar, pretendemos delinear o lugar que o elemento do terror ocupa para a estruturação desses regimes e seu modo de operação para solidificá-los; ou seja, temos em vista abordar o papel essencial que o terror desempenha no processo de cooptação da massa.

É conveniente notar que, em ambos os casos, sustentamos nossa argumentação sob a égide de Arendt - em especial na obra supracitada. Ressaltamos também que a circunscrição opcional ao trabalho da filósofa alemã acontece apenas por uma escolha metodológica. Ademais, não é o nosso propósito tentar elaborar uma salvaguarda, nem uma ilibação, para o envolvimento das massas, cada qual à sua maneira, no seio dos totalitarismos. Não é, sequer, uma tentativa de realizar uma trilha psicológica e subjetiva acerca das motivações pessoais - 
algo, se não impossível, altamente impróprio para uma especulação acadêmica. Antes disso, nosso empenho está em tentar compreender como as sociedades de massa puderam ser cooptadas e colocadas em funcionamento pela engrenagem desses regimes.

\section{O alvorecer dos regimes totalitários: a transformação da sociedade de classes em uma sociedade de massa}

Em primeiro lugar, evemos notar que o conceito de totalitarismo se constrói sobre os escombros deixados pela Grande Guerra. No arrasto do notável conflito mundial, que redesenhou as fronteiras psicológicas e o mapa da Europa, eclodiram três experiências históricas que darão sustentação aos movimentos totalitários - além de marcar o curso da humanidade de maneira indelével: o Fascismo italiano, o Nacional-Socialismo alemão e a do Stalinismo da União Soviética.

Esses três regimes, conforme salienta Enzo Traverso (2002, p. 5) em Il totalitarismo: storia di un dibattito, apesar de apresentarem diferenças que são substanciais, sobretudo na forma de organização, revelavam características inéditas, cuja afinidade solicita uma aproximação comparativa. Com efeito, o êxito de cada um, em especial no uso bem-sucedido do mecanismo criminal, despertou novas interrogações acerca da relação que podemos estabelecer entre o poder político e a sociedade civil, isto é, entre a violência e o Estado. De qualquer modo, ao lado das inúmeras peculiaridades que diferenciam cada modo de governo, todos eles apresentavam-se aos observadores claramente como uma antítese do Estado de Direito. Nesse mote, tanto o Nazismo, como o Stalinismo e o Fascismo, não apenas contradiziam o sistema institucional das leis positivas, mas assumiam uma posição de rejeição ao Liberalismo - também cambaleante - em suas características mais fundamentais.

Entretanto, o dado perturbador que brota dessa constatação é o de que, segundo Traverso (2012, p. 8), os totalitarismos se manifestam como filhos da modernidade. O alvorecer da dominação total, que é colocada em movimento pelos regimes totalitários, parte do pressuposto da atividade de um elemento que não nos é inteiramente estranho: as sociedades de massa. Dito de outro modo, esses regimes são uma marca do nosso tempo, uma cicatriz cujo ferimento foi oriundo da ação de "atração" das massas. Na verdade, esses sistemas germinaram, em geral, no seio de uma comunidade que testemunhava o ocaso das sociedades de classes. Ou, ainda - e aqui mais claramente aqueles que se inscrevem sob o Nazi-Fascismo -, em uma sociedade urbana e industrial, onde o fenômeno da "nacionalização das massas" havia sido posto em aceleração pelos desdobramentos da Grande Guerra. 
Mas, afinal, como podemos caracterizar essa "massa" sobre a qual se assenta essas formas de totalitarismo? Como a transformação da sociedade de classes para a sociedade de massa pode ter implicado no surgimento desses regimes?

Sobre isso, Arendt, em seu esforço inspirador para compreender a relação das massas nas dinâmicas totalitárias, pondera que, tanto a transformação de uma sociedade de classes em uma sociedade de massas, quanto a "concomitante eliminação da solidariedade grupal", são "condições sine qua non do domínio total" (ARENDT, 2012, p. 424). Ora, a queda das "paredes protetoras das classes" foi o componente responsável por transformar as "maiorias adormecidas", que ocupavam a retaguarda de todos os partidos, em uma "grande massa desorganizada e desestruturada de indivíduos furiosos que nada tinham em comum", exceto uma noção vaga de que "as esperanças partidárias eram vãs" (idem, p. 444). Sobre isso, como nos lembra Aron (1998, p. 252), Arendt identificava, nas classes, grupos integrados no interior de uma coletividade nacional, que conservava algo da consciência comum dos Estados. A massa, ao contrário, seria o resultado da dissolução dessas classes e o reagrupamento dos indivíduos dispersos. Assim, os movimentos totalitários possuem por objetivo a organização da massa dispersa oriunda do ocaso das classes.

É nessa atmosfera de colapso da sociedade de classes que a psicologia do homem de massas da Europa foi desenvolvida. Na nova conjuntura florescente, o sentimento e a consciência pessoal de "desimportância" e de "dispensabilidade" deixavam de ser a "expressão da frustração individual" e tornava-se um "fenômeno de massa" (ARENDT, 2012, p. 445). Consequentemente, devemos reconhecer que essas massas são o produto dos fragmentos da sociedade atomizada, "cuja estrutura competitiva e concomitante solidão do indivíduo eram controladas apenas quando se pertencia a uma classe" (idem, p. 446).

Agora, os indivíduos, absolutamente isolados, são engolidos por uma organização maciça. Pois, a lealdade aos regimes, que é, enfim, a base psicológica para o domínio total, apenas pode grassar em seres humanos "completamente isolados", que, "desprovidos de outros laços sociais - de família, amizade, camaradagem - só adquirem o sentido de terem lugar neste mundo quando participam de um movimento, pertencem ao partido" (ibidem, p. $454)^{2}$. O totalitarismo que se preza, reforça Arendt (ibidem, p. 452), chega ao ponto em que

\footnotetext{
${ }^{2}$ Podemos, por exemplo, aludir à dependência psicológica que o Partido exerce em seus adeptos através do caso de Eichmann. Conforme narra Arendt (1999, p. 43-44) em Eichmann em Jerusalém, no dia 8 de maio de 1945, data oficial da derrocada alemã, Eichmann se deu conta de que a partir de então deveria viver sem ser membro de uma coisa ou outra. Segundo seu próprio relato, "senti que teria de viver uma vida individual difícil e sem liderança, não receberia diretivas de ninguém, nenhuma ordem, nem comando me seriam dados, não haveria mais nenhum regulamento pertinente para consultar - em resumo, havia diante de mim uma vida nova".
} 
tem de acabar com a existência autônoma de qualquer atividade que seja. O isolamento, portanto, é o alicerce sobre o qual os regimes totalitários se escoram para capturar a coletividade. Se, por um lado, esse sentimento já estava no subsolo da sociedade de massa, por outro ele é levado a níveis extremos pela organização totalitária.

São nesses indivíduos, imersos na profunda percepção de isolamento, que os líderes totalitários buscam o respaldo para seus regimes. Contudo, como propõe Traverso (2002, p. 9), essa massa desorganizada deve constituir-se em torno de uma comunidade: deve fundir-se em um "corpo coletivo" através da encarnação na figura de um povo, de uma nação ou de uma raça. A ação que constitui uma organização comunitária, de identidade generalista, deve ser cimentada por uma espécie de fé; incorporada por um líder; animada pelo entusiasmo; mobilizada permanentemente. Afinal, com promessas escatológicas, ícones e rituais, o totalitarismo se apresenta como uma "religião laica", que "desagrega a sociedade civil e transforma o povo em uma comunidade de fiéis" ${ }^{3}$.

Parece ser inerente ao totalitarismo que, em uma aglomeração dessa natureza, todas as individualidades sejam subsumidas em função de uma massa indiferenciada. A subjetividade é estraçalhada, e o particular é colocado inteiramente à mercê da multidão - e, por consequência, aos propósitos do movimento totalitário. Como Arendt afirmará posteriormente, existe a construção de um "cinturão de ferro" que dissolve a pluralidade dos indivíduos em Um-Só-Homem de dimensões gigantescas. Quer dizer, o indivíduo é "esmagado, absorvido e anulado pelo Estado, que aparece como uma unidade compacta, na qual as singularidades se dissolvem e os homens se fazem massa" (TRAVERSO, 2002, p. 9).

Ao contrário daquilo que facilmente poderíamos supor, a principal característica dos indivíduos que brotam do desmoronamento da sociedade de classes não é nem a brutalidade nem sequer a rudeza. Mas, o próprio isolamento extremado e a destruição total das relações sociais. O terror totalitário opera, justamente, com essa espécie de "material humano", retraído na atomização e com os laços sociais em pedaços. Em um ambiente "societário" dessa natureza, o regime totalitário encontra uma atmosfera propícia para o seu surgimento e propagação. Se tanto o isolamento quanto o ocaso das relações sociais já são um reflexo da sociedade de massa, esses regimes se constroem em torno dessa premissa, reforçando entusiasmadamente tais características. Sob essa perspectiva, diz Arendt (2002, p. 446), o

\footnotetext{
${ }^{3}$ Nesse sentido, Marcel Gauchet vai ainda mais além. Para o estudioso, o totalitarismo não apenas age como uma forma de religião secular, mas, ele próprio, se transforma em uma religião secular. Sobre isso, cf. GAUCHET, Marcel. Totalitarisme, idéocratie, religion séculière. In: L'Avènement de la Démocratie III: À l'épreuve des totalitarismes 1914-1974. Paris: Gallimard, 2010, p. 516-551.
} 
homem da massa, oriundo da sociedade do "Estado-nação", até então dominada por classes "cujas fissuras haviam sido cimentadas pelo sentimento nacionalista", ao caírem no relento e no desamparo de sua existência, "tenderam para um nacionalismo especialmente violento".

Enfim, com esse curto percurso pregresso, podemos formar um arcabouço teórico razoável para apresentarmos o modo através do qual o terror impera na atividade totalitária. Isto é, o cenário ruinoso da sociedade de classes, no período subsequente a Grande Guerra, e o advento da sociedade de massa, mostram-se como condições ideias para a incubação dos regimes totalitários no seio daqueles países predispostos (por motivações históricas, sociais, etc.) à resignação da multidão. Na realidade, a dispersão e o isolamento dos indivíduos, provenientes da queda das classes, constituíram-se como um ambiente extremamente propício ao surgimento dessa forma de governo inédita.

Assim, a sociedade no interior da qual surge o totalitarismo é aquela dos indivíduos já atomizados, mas que, agora, no alvorecer totalitário, são colocados a serviço dos propósitos ideológicos dos Partidos. No isolamento excruciante, a massa é absorvida pelo Estado e engolida pelo totalitarismo. Como a própria definição do "governo totalitário" deixa entrever, o domínio estatal lança seus tentáculos sobre todas as atividades humanas ${ }^{4}$. O totalitarismo, diluído em todos os setores, opera através da instrumentação do terror para envolver a comunidade em um "desígnio", congregando-a ao redor de uma crença sobre uma raça, uma nação ou um povo - cujos propósitos correspondem a uma finalidade "natural" da humanidade. Ora, é propriamente sob esse panorama que podemos descortinar o uso e a importância do terror para os regimes totalitários.

\section{O caráter essencial e operacional do terror}

Em primeiro lugar, devemos notar que o terror, arquiteto do totalitarismo, possui, no quadro histórico das formas de governo, uma configuração que é inteiramente nova. Como modo de ação governamental, o terror totalitário é algo que não apresenta paralelos históricos: estamos diante de uma matéria que é objetivada de maneira completamente original. Ou, para dizer com Aron (1998, p. 262), a experiência dos totalitarismos nos oferece um terror de estilo ainda desconhecido.

Essa estrutura é diferente, por exemplo, do clássico terror ditatorial. Comparativamente, o terror tirânico diferencia-se do terror totalitário por uma questão de

\footnotetext{
${ }^{4}$ Para Ian Kershaw (1996, p. 111), toda distinção puramente teórica entre domínio público e esfera privada havia desaparecido. No caso Nazista, como elucida através das palavras de Robert Ley, chefe da Frente Alemã para o Trabalho, "apenas o sono era agora uma tarefa individual".
} 
proporcionalidade de extensão: enquanto o primeiro é circunscrito e atua sobre um número limitado de indivíduos, o segundo desafia o conjunto da coletividade, uma vez que todos estão sujeitos a experimentá-lo, inclusive os cidadãos inofensivos e carentes de opiniões políticas (ARENDT, 2012, p. 451-2). Logo, é no interior de um regime totalitário, que absorve a sociedade civil dentro do Estado ao ponto de aniquilá-la ${ }^{5}$, que o terror revela sua função vital. Ou seja, se o totalitarismo apresenta-se como uma categoria inédita no cenário das formas de governo, isso se deve, em parte, pelo uso que faz do terror.

Com isso, é precisamente o terror, diluído em todos os estratos humanos, um campo de abordagem através do qual podemos assimilar o movimento de cooptação das massas. Nesse sentido, Arendt (2012, p. 618), por exemplo, é peremptória quando traça a distinção entre os governos constitucionais, tirânicos e totalitários. De acordo com a filósofa alemã, "se a legalidade é a essência do governo não-tirânico e a ilegalidade é a essência da tirania, então o terror é a essência do domínio totalitário". A partir disso, nosso esforço, está em averiguar como o terror se constitui como a espinha dorsal do totalitarismo.

Conforme temos insistido, quando situamos o governo totalitário diante dos governos constitucionais ou tirânicos, ele se apresenta de maneira original. Certamente, o conjunto das disposições totalitárias estabelece um desafio às leis positivas. Contudo, isso não significa que sua operação ocorra na pura arbitrariedade ou na ausência de leis. Como teoriza Arendt (2012, p. 613), devemos reconhecer que tanto o regime Nazista quanto o Stalinismo afirmavam obedecer a leis de modo rigoroso e inequívoco. No entanto, as Leis que norteiam os regimes totalitários se distanciam dos decretos positivos por uma noção de profundidade, pois fundam sua ação no elemento que acreditamos estar na "origem de todas as leis". Enquanto o regime hitleriano, no âmago das pretensões raciais, curvava-se às leis da Natureza, o regime stalinista, no desenrolar da luta de classes, prestava continência às leis da História.

Porém, existe aqui uma especificidade. No desdobramento do totalitarismo, o próprio termo "lei" sofreu uma mudança significativa. Se as leis positivas estavam destinadas a operar como "elementos estabilizadores" para o curso da ação humana, eternamente mutável, nos regimes totalitários "todas as leis se tornam leis de movimento". Enquanto no governo

\footnotetext{
${ }^{5}$ Sobre isso, argumenta Traverso (2002, p. 11), os regimes totalitários "postulam o absorvimento da sociedade civil, até o seu aniquilamento, no Estado". Isto é, estamos diante da abolição da dicotomia clássica entre o Leviatã e o Behemoth. Por um lado, há a conservação da "potência de uma ordem absoluta que submete à sua vontade a multidão dos seus súditos". Mas, por outro, essa fachada "esconde um reino de caos e da destruição, um domínio negador do princípio próprio da polis". Acerca da dissolução da sociedade civil pelo Estado totalitário, cf. SCHMITT, Carl. The Way to the Total State. In: Four Articles: 1931-1938. Trad. Simona Draghici. Corvallis: Plutarch Press, 1999, p. 1-18. Cf. também MUSSOLINI, Benito; GENTILE, Giovanni. La Dottrina del Fascismo. In: Opera Omnia. Vol. XXXIV. Firenze: La Fenice, 1961, p.115-138.
} 


\section{REVISTA ALAMEDAS Vol. 4, n. 2, 2016 e-ISSN 1981-025}

constitucional as leis buscam equilibrar o fluxo humano, no governo totalitário, tanto a Natureza quanto a História "deixam de ser a força estabilizadora da autoridade para as ações dos homens mortais, elas próprias tornam-se movimento" (idem, p. 615).

Neste lugar, segundo Arendt (ibidem, p. 616-7), estamos diante de uma "tremenda mudança intelectual que ocorreu em meados do século XIX" que consistiu na recusa de encarar qualquer coisa "como é", na tentativa de interpretar tudo como simples estágio de algum desenvolvimento posterior. Então a "lei", prossegue, "deixa de expressar a estrutura de estabilidade dentro da qual podem ocorrer os atos e os movimentos humanos, para ser a expressão do próprio movimento". Ou seja, a lei deixa de ser o postulado constitucional do Estado, que expressava os limites fronteiriços e as limitações dentro das quais as atividades humanas deveriam ocorrer, e se manifesta, ela própria, como a encarnação de uma mutabilidade que nunca cessa. Transformar as leis da Natureza e da História em movimento significa desenraizar qualquer possibilidade de estabilidade: a lei, no totalitarismo, é desabrigada de seu caráter clássico de circunscrição para também se transformar em movimento.

A razão da transformação de um núcleo estabilizador para um de puro movimento corresponde ao alastramento da incerteza por todos os segmentos da coletividade. Se a lei não pode ser a garantia da estabilidade, existe, portanto, um contínuo fluxo das ações governamentais em direção aos propósitos dessas leis fixadas pela Natureza ou pela História. Movimentar-se, de acordo com essas leis, significa despender todas as medidas necessárias para a conformidade final do regime totalitário ${ }^{6}$.

Assim, a lei do movimento é assimilada pelo totalitarismo, e o terror atua como o mecanismo através do qual o movimento é levado a efeito. Ou seja, o terror é o elemento que proporciona a efetivação cadenciada do movimento em direção aos propósitos do povo [germânico] ou do Estado sem classes [soviético]. Enquanto no governo constitucional há a necessidade da promulgação de leis positivas para a conversão e a realização do "imutável ius naturale" ou a "eterna lei de Deus", no corpo totalitário "o lugar das leis positivas é tomado pelo terror total, que se destina a converter em realidade a lei do movimento da história ou da natureza" (ibidem, p. 617, grifo nosso). Em suma, a "facticidade" da lei do movimento está intrinsecamente relacionada com a instrumentação do terror.

\footnotetext{
${ }^{6}$ Entretanto, o movimento não é um acontecimento episódico no totalitarismo, mas uma característica infindável. Se "é lei da natureza eliminar tudo o que é nocivo e indigno de viver, a própria natureza seria eliminada quando não se pudessem encontrar novas categorias nocivas e indignas de viver". Ou, se é a "lei da história que, numa luta de classes", certas classes "fenecem", "a própria história humana chegaria ao fim se não se formassem novas classes que, por sua vez pudessem "fenecer" nas mãos dos governantes totalitários" (ARENDT, 2012, p. 617).
} 
Do ponto de vista governamental, o que significa situar o terror como a essência e a instituição inexorável do totalitarismo?

O objetivo do terror enquanto realização da lei do movimento é proporcionar à força da Natureza ou da História um livre propagar-se por toda humanidade, eliminando qualquer foco voluntário de resistência ou interrupção. Apenas nesse sentido podemos falar de uma "estabilização" promovida pelo terror: os homens são imobilizados para que as forças sobrehumanas possam selecionar os "inimigos da humanidade contra os quais se desencadeia o terror" (ibidem, p. 618). De fato, a essência do regime totalitário assume uma feição instrumental para a seleção e a eliminação dos "inimigos objetivos" determinados pela Natureza ou pela História.

Esse terror, cujo propósito é a "fabricação da humanidade", sente-se a vontade para eliminar indivíduos pelo bem da espécie, para sacrificar partes em benefício do todo. Nesse caso, a função do terror total como essência do regime totalitário é "proporcionar às forças da natureza ou da história um meio de acelerar o seu movimento" (ibidem, p. 620). Dito de outro modo, o terror é o componente responsável por imprimir uma aceleração nas leis "sobrehumanas", algo que, por si mesmas, jamais conseguiriam alcançar.

Disso, podemos nos avizinhar da conclusão de que o gênero do terror totalitário é assentado sobre um sentimento de medo contínuo: o medo do desconhecido; o medo de tornar-se a próxima vítima do exercício de uma violência cuja origem é desconhecida; o medo de tomar o lugar daqueles que agora são os inimigos objetivos; o medo de ser arrastado e transformar-se em alvo da inexorável lei do movimento. Nesse caso, o fundamento do Estado total parece residir em uma potencialidade do medo. O terror é essencial não somente como instrumento efetivo de violência, mas uma característica constante que petrifica os indivíduos. A humanidade, sob o jugo de um governo totalitário, subsumida na coletividade amorfa, precisa carregar consigo o medo ininterrupto - muito embora, factualmente, não se tornem vítimas da impetuosidade totalitária.

Por um lado, figura como verdadeira a afirmação de que, com o tempo e com a alta adesão da massa ao ímpeto dos regimes, o exercício efetivo e constante da violência acaba por abrandar-se. Porém, por outro lado, encontramos a instalação de uma espécie de temor virtual como um componente indispensável - e, por isso mesmo, essencial - para cimentar o totalitarismo ${ }^{7}$. Ou seja, deve existir um sentimento transversal de que o papel de vítima

\footnotetext{
7 Kershaw (1996, p.108-9), por exemplo, afirma que o componente central do totalitarismo sempre foi a "natureza e a extensão do terror". Nesse caso, podemos falar de uma redução da extensão do terror, como no
} 
também cabe aos demais. Nesse caso, o terror é a essência do totalitarismo não apenas por proporcionar as condições para o nascimento do regime, mas também por ser uma característica que não pode ser suprimida sem seu ocaso. Como explica Aron (1998, p, 262), a partir do momento em que testemunhamos a punição de um "criminoso virtual", cuja ação poderia "ter sido nociva à revolução ou aquele que, em virtude da sua pertença a um grupo condenado pela história, poderia sê-lo amanhã", testemunhamos também o alastramento da incerteza, da sensação do completo abandono, pois todos se tornam, enfim "prisioneiros de uma fatalidade implacável", "vítimas de uma força desumana".

Com essa extensão, o terror se torna "soberano". Agora, o título de "culpado" ou "inocente" não podem mais ser atribuídos às ações individuais. Sobre isso, argumenta Baehr (2010, p. 73), no regime totalitário a culpabilidade adere às categorias ao invés de pessoas aos "inimigos objetivos", como as classes moribundas ou as raças inferiores, impróprias para esse mundo. Nesse cenário, a sentença de morte é pronunciada por tribunais da Natureza ou da História. Porém, como esses governos fundam-se na lei do movimento, quando um inimigo objetivo é consumido, outro toma seu lugar. A incerteza assume um aspecto avassalador: ninguém sabe quem será o próximo alvo de expurgos ou o próximo inimigo do povo. $\mathrm{Na}$ flexibilidade do movimento, ninguém pode estar certo que a ortodoxia hoje não se transmutará amanhã em heresia.

Nessa instância, podemos reconhecer a especificidade da sociedade de massa sob o terror do governo totalitário. Os indivíduos dispersos são organizados através da construção de um "cinturão de ferror", que os cinge de tal forma que é como se "a pluralidade se dissolvesse em Um-Só-Homem de dimensões gigantescas" (ARENDT, 2012, p. 619). Enquanto as leis positivas nos regimes constitucionais eram responsáveis pela construção de fronteiras e de canais de comunicação entre os homens, no caso totalitário ambos eram destruídos. Agora, acentua Arendt (idem, p. 620), no cinturão de ferro do terror, "que destrói a pluralidade dos homens e faz de todos aquele Um que invariavelmente agirá como se ele próprio fosse parte da corrente da história ou da natureza", finalmente "encontrou-se um meio não apenas de libertar as forças históricas ou naturais, mas de imprimir-lhes uma velocidade que elas, por si mesmas, jamais atingiriam".

Ao solapar a sociedade civil, ao desmantelar toda atividade de vida associativa, ao lançar os indivíduos para um quadro de isolamento absoluto, o terror impera de maneira

caso da era pós-Stalin, de uma "regressão muito sensível de sua arbitrariedade e de sua imprevisibilidade". Mas, certamente, "seria errado [...] subestimar a permanência da repressão". 
soberana. O terror, enfim, resulta em algo que soa quase paradoxal: por um lado, acentua a individualidade e desolamento dos homens sob seu domínio; por outro, serve-se desse isolamento para aglomerá-los em uma massa indiferenciada, cuja existência de cada particular só encontra sentido se, e tão somente se, fizerem parte desse movimento.

Por último, a imbricação da díade "terror" e "movimento" no governo totalitário desvela o caráter operacional dessa essência. Entretanto, uma "funcionalidade" do terror enquanto essência emperra numa questão conceitual. Sobre isso, Arendt (2012, p. 621) recava uma discussão que remonta a Montesquieu para destacar que o elemento que atribui movimento ao corpo político não pode ser encontrado "em sua essência, porque essa essência [...] sempre foi definida com vistas à sua permanência". Então, o que falta à definição de governo é aquilo que o pensador francês chamou de "princípio de ação", que, sendo diferente para cada forma de governo, "inspiraria governantes e cidadãos em sua atividade pública". Assim, numa monarquia, o princípio de ação é a honra; numa república, a virtude, numa tirania, o medo.

O problema, nesse caso, está em que o totalitarismo parece não apresentar nenhum "princípio" correspondente. O que, como se questiona apropriadamente Baehr (2010, p. 74), proporciona as coordenadas mentais, ou, ao menos, um modo de orientação, para os súditos totalitários? Pois, o terror não é suficiente para definir a conduta humana em sua totalidade. Conforme insiste Baehr, "nem todo mundo cairá igualmente dentro de sua órbita". E, aqueles que são arrebatados pelo terror, podem ainda "exigir sinais para guiá-los em um mundo de vítimas escolhidas aleatoriamente e que muda de pronunciamento perenemente".

Aqui, responde Arendt (2012, p. 623), o totalitarismo "introduziu um princípio inteiramente novo no terreno das coisas públicas que dispensa inteiramente o desejo humano de agir", mas, também, atende à "desesperada necessidade de alguma intuição da lei do movimento", da qual "dependem todos os destinos pessoais". Os habitantes de um país totalitário são "arremessados e engolfados num processo da natureza ou da história para que se acelere o seu movimento". Dessa forma, "só podem ser carrascos ou vítimas de sua lei inseparável". Nessa lógica, o princípio de ação introduzido pelo totalitarismo é, antes, um substituto para ele, é uma "preparação bilateral", para que cada um "se ajuste igualmente bem ao papel de carrasco e ao papel de vítima": entra em ação, então, a ideologia.

Metodologicamente falando, uma investigação pormenorizada acerca da atuação da ideologia excederia, de modo considerável, nosso esforço. Porém, convém pontuar que esse "princípio de ação" substituto atua como uma forma de explicação do mundo, integrando 
todos os acontecimentos em uma lógica dedutiva que funciona como um revestimento do real. Nesse cenário, o terror funciona como o elemento que permite transformar a ideologia em algo factual. Ou, em suma, o terror é a condição de efetividade para a ideologia, que se apresenta como um modo de contenção dos eventos que são, por natureza, puramente contingenciais. A máquina ideológica coloca os indivíduos em ação de acordo com os propósitos totalitários; conformidade que, outra vez, é assegurada pelo terror ${ }^{8}$.

\section{Considerações finais}

Enfim, com o percurso programático aqui desenvolvido, no encalço do pensamento de Arendt, buscamos delinear um modo através do qual a sociedade de massa pôde ser aliciada, absorvida e colocada em movimento pela dinâmica totalitária. Nesse sentido, objetivamos ressaltar os pilares, ou as condições sine qua non, para o alvorecer e o amparo dos regimes totalitários. Assim, de um lado, situamos a caracterização da forma de "organização social" sobre a qual esse modo de governo se escora para solidificar-se enquanto regime; e, de outro, tentamos ressaltar o papel e o modo de operação do terror no processo de envolvimento dos indivíduos nos projetos totalitários, ou seja, no movimento de cooptação da massa.

Certamente, o processo histórico de arruinamento da sociedade de classes - conquanto efeito colateral da Grande Guerra, da devastação geopolítica, do fomento dos sentimentos nacionalistas, da incipiência das "ideologias" - é, certamente, um dado preliminar de importância fundamental para o alvorecer desses regimes. Contudo, a mera transformação das classes em massa não significa, automaticamente, a formação de governos totalitários. E, talvez seja isto o que nos toca enquanto receio da repetição da história: nossa sociedade de massa é o ground zero para o totalitarismo. Ou seja, foi justamente no seio de uma configuração social não muito distante da nossa que os absurdos humanitários do século XX encontraram sua origem. Então, o totalitarismo não apenas se revela como objeto de estudo enquanto uma forma política relativamente nova - como "conceito" -, mas também como um modo de criarmos o instrumental teórico para precaver-se contra um possível retorno ${ }^{9}$.

\footnotetext{
${ }^{8}$ Sobre a questão da ideologia, cf. a parte final das Origens do Totalitarismo, p. 624-632. A respeito da relação entre ideologia e terror, cf. ARON, Raymond. Idéologie et terreur. In: Démocratie et totalitarisme. Paris : Gallimard, 1965, p. 262-281.

${ }^{9}$ Essa potencialidade para o retorno dos regimes totalitários parece se encaixar na possibilidade de reincidência dos genocídios propiciados pelo Nazismo, segundo afirma Arendt em Eichmann em Jerusalém. Na ocasião, sustenta que "Faz parte da própria natureza das coisas humanas que cada ato cometido e registrado pela história da humanidade fique com a humanidade como uma potencialidade, muito depois da sua efetividade ter se tornado coisa do passado" (ARENDT, 2016, p. 295-6).
} 
Conforme procuramos apontar, nesse cenário de transição entre a sociedade de classes, a sociedade de massa e o totalitarismo, o terror desempenhou uma função chave. Agora, em um salto inovativo, esse elemento não apenas é instrumentalizado pelo Estado - algo que as ditaduras, de algum modo, já haviam realizado. Mas, o terror totalitário, quando congregado com as inspirações de um projeto político que possui um telos imanente de sublevação de um conjunto de indivíduos em detrimento dos demais, torna-se a própria estrutura do totalitarismo.

Esse terror aparece como um valor ambivalente enquanto essencialidade dos regimes: em primeiro lugar, seu exercício opera como uma condição à germinação dos totalitarismos: a sociedade de massa apenas pode ser colocada em movimento em torno dos propósitos totalitários sob o jugo do terror. Em segundo lugar, se o exercício da violência não é uma constante para o totalitarismo, o temor virtual propiciado pelo terror é algo indispensável para a manutenção dos regimes: o receio de tornar-se a próxima vítima é necessário para a conservação do "cinturão de ferro". Sob esse panorama, ele é um ingrediente de valor singular para a galvanização dos indivíduos em torno de uma ideologia sancionada pelos Partidos. Embora possa ser leviano depositar nesse aspecto o único fator de cooptação da massa, não podemos, simplesmente, minimizar sua importância para o envolvimento dos indivíduos.

Obviamente não queremos, com isso, subestimar a participação da massa em favor das atividades criminosas implícitas no desenrolar dos totalitarismos, ou atribuir um indulto para esses grupos nos países totalitários. Permanece desconcertante, como notou Arendt, pensarmos na adesão da coletividade a diversos projetos nefastos. Em todos os casos, é inquestionável o comprometimento da massa. Ora com conivência, entusiasmada ou resignada, ora com indiferença. O mais perturbador, nesse caso, talvez seja o fato de que as vozes de dissidência dos regimes totalitários foram logo silenciadas. A operação do terror parece ser implacável. Os opositores dos regimes, pelos diversos mecanismos de violência, ou são rapidamente suprimidos, ou, pela consciência de que a ação solitária é um ato de suicídio sem qualquer efeito para alterar a situação, são engessados. Por isso, a exterioridade de "consenso" no interior do totalitarismo tem uma causa impactante: há consenso apenas porque o dissenso é arrasado pela operacionalidade do terror ${ }^{10}$.

\footnotetext{
${ }^{10}$ Nesse sentido, parecem relevantes as memórias de guerra de Peter Bamm, médico alemão, citadas por Arendt (1999, p. 253-4) em Eichmann em Jerusalém. Acerca dos horrores do genocídio, diz Bamm "sabíamos disso. Não fizemos nada. Qualquer um que protestasse seriamente ou fizesse alguma coisa contra a unidade de assassinato teria sido preso em 24 horas e desaparecido. Faz parte dos refinamentos dos governos totalitários do nosso século que eles não permitam que seus oponentes morram a morte grandiosa, dramática dos mártires. $\mathrm{O}$ Estado totalitário deixa seus oponentes desaparecerem em silencioso anonimato. É certo que qualquer um que
} 
Diante desse contexto de natural pessimismo, novamente parece ser Arendt que nos lança certa luz. Pois, os regimes totalitários, como as outras formas de governo, não são incólumes à corrupção. A estabilidade, que buscam transmitir, não é nada senão um revestimento para o caos. As experiências históricas comprovam que esses governos podem desfazer-se por duas frentes: pela derrota externa, imposta por condições militares, como no caso do Nazi-Fascismo; ou por uma derrota interna, como o esborrachamento da União Soviética.

Nesse caso, mais esperançoso que o fatídico destino de uma derrocada nos campos de batalha, está o fato de que o fluxo de natividade, mesmo sob o terror total, não cessa: os homens continuam nascendo e morrendo. Cada novo nascimento representa um novo começo que surge para o mundo. Isto é, um novo mundo em potencial passa a existir. Quando o terror não consegue mais cercear a fonte de liberdade que está no nascimento dos indivíduos, a ruína interna do totalitarismo começa a articular-se. No nascimento não atravessado pelos instrumentos totalitários, vemos um embrião da liberdade. Ou, como termina Arendt (2012, p. 639), "cada novo nascimento garante esse começo; ele é, na verdade, cada um de nós".

\section{REFERÊNCIAS}

ARENDT, Hannah. Eichmann em Jerusalém: um relato sobre a banalidade do mal. São Paulo: Companhia das Letras, 1999.

Origens do Totalitarismo: antissemitismo, imperialismo, totalitarismo. Trad. de

Roberto Raposo. São Paulo: Companhia das Letras, 2012.

The Origins of Totalitarianism: new edition with added prefaces. New York: Harvest Book, 1976.

ARON, Raymond. L'essenza del totalitarismo. In: Machiavelli e le tirannie moderne. Traduzione di Mario Baccianini. Roma: Edizioni Seam, 1998, p. 249-272.

BAEHR, Peter. Hannah Arendt, Totalitarism, and the Social Sciences. Stanford: Stanford University Press, 2010.

KERSHAW, Ian. Retour sur le totalitarisme: le nazisme et le stalinisme dans une perspective comparative. In: Esprit. N'218, janeiro-fevereiro, 1996, p. 101-121.

TRAVERSO, Enzo. Il Totalitarismo: Storia di un dibattito. Milano: Bruno Mondadori Editori, 2002.

Le totalitarisme. Paris: Éditions du Seuil, 2001.

tivesse ousado morrer para não tolerar silenciosamente o crime teria sacrificado sua vida em vão. Isso não quer dizer que tal sacrifício teria sido moralmente sem sentido. Teria apenas sido praticamente inútil". 